\title{
Understanding the mechanisms responsible for the beneficial effect of hammer peening in welded structure under fatigue loading

\author{
F.Lefebvre $^{1, a^{*}}$, C. Revilla-Gomez ${ }^{2}$, J-Y, Buffiere ${ }^{2}$, C. Verdu ${ }^{2, b}$, and C. Peyrac ${ }^{1}$ \\ ${ }^{1}$ Cetim, 52 avenue Félix Louat, 60304 Senlis, France \\ ${ }^{2}$ Laboratoire Mateis, Insa de Lyon, 69621 Villeurbanne-Cedex, France \\ afabien.lefebvre@cetim.fr, ${ }^{b}$ catherine.verdu@insa-lyon.fr
}

Keywords: Hammer peening; Residual stress; fatigue.

\begin{abstract}
.
The influence of hammer peening on the fatigue resistance of high strength welded joints of the high strength structural steel S690 has been investigated. The effect of three different parameters has been studied: geometrical effect (shape of weld tooth, roughness), microstructural effect (grain microstructure, strain-hardened depth) or residual stress effect evaluated by X-ray diffraction. Two types of hammer peening are investigated (manual and automatic).
\end{abstract}

\section{Introduction}

In steel constructions (cranes, bridges, cars, agricultural or mining machinery ...), welding is, by far, the most popular joining method.The large temperature variations, which occur during welding, induce phase transformations in ferrous materials. These phase transformations have a detrimental effect on the fatigue properties of the welded structure, which is made worse by the presence of notch stress concentration and residual tensile stresses [3]. In order to improve fatigue properties of steel welded components, hammer peening may be performed [2]. This technique consists in deforming the weld toe plastically with repeated impacts of a needle like tool. A substantial fatigue life improvement has been observed after hammering in high strength steels [13]. The classical explanation for this beneficial effect is that the process introduces large compressive stresses, which tend to decrease the tensile residual stress state arising from the welding process [3]. However, aside from its influence on residual stresses, hammer peening has a direct influence on the geometry of the weld toe and on the material microstructure, the latter being rarely considered. In this work, those three factors have been studied in order to assess their respective influence.

\section{Materials and Experimental Methods}

A low-alloy high strength structural steel, grade S690 is considered in this study. The material was supplied as 10 mm-thick plates, which were butt welded with Class "C" quality knowing that the quality level B corresponds to the highest requirement on the finished weld [8]. After welding the weld toe regions have been manually or automatically hammered using a pneumatic hammer as shown in Figure 1. The radius of the hammer pin used is $R=2 \mathrm{~mm}$ and the impacts are produced with a frequency of $80 \mathrm{~Hz}$. The displacement speed of the hammering tool along the weld line is around $18 \mathrm{~cm} / \mathrm{min}$ in the case of manual hammering (with several going and coming) and $10 \mathrm{~cm} / \mathrm{min}$ for automatic hammering, (pneumatic hammer mounted on a robot arm, which is displaced at constant speed along a straight line approximately parallel to the weld line).

The topography of the weld toe is described through two parameters: the radius of the groove created by the hammering tool and its depth (Figure 2). Both have been measured with a 3dimensional non-contact optical profilometer. Table 1 presents the values of the measured radii and depths of the weld toe as defined in Figure 2. A groove with a similar geometry has been produced by mechanical machining (milling) on as welded samples in order to try and assess the geometrical 
effect of hammering. Post weld heat-treatment has been performed for $1 \mathrm{~h}$ at $500^{\circ} \mathrm{C}$ to obtain stress free samples.

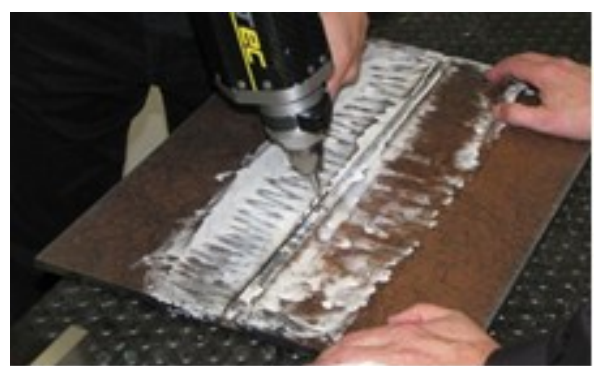

Manual hammering

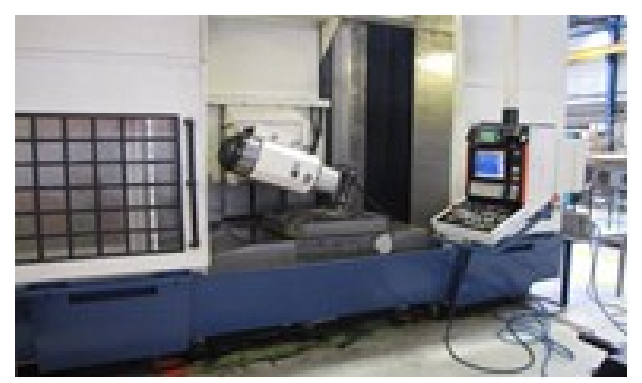

Automatic hammering

Figure 1 Photographs of the hammering process. In the case of automatic hammering the hammer is held by a robot arm, which translates the tool along a straight path aligned with the weld toe.
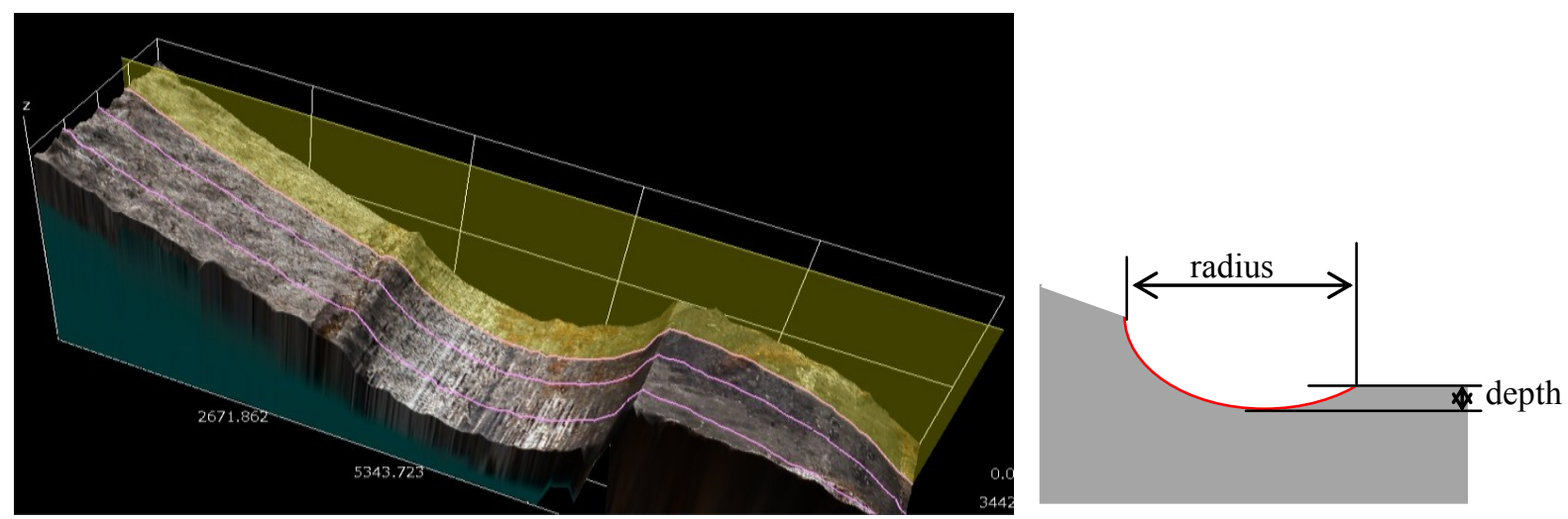

Figure $23 \mathrm{D}$ profile of machined welded toe and schematic drawing of the weld toe

Table 1 Radius and depth of the weld toe

\begin{tabular}{|l|l|l|l|}
\hline & As welded & Hammered & Machined \\
\hline Radius & $0.4 \mathrm{~mm}$ & $2.56 \mathrm{~mm}$ & $2.52 \mathrm{~mm}$ \\
\hline Depth & $0 \mu \mathrm{m}$ & $140 \mu \mathrm{m}$ & $300 \mu \mathrm{m}$ \\
\hline
\end{tabular}

Residual stresses determination has been carried out by X-Ray diffractometer using $\mathrm{Cr}-\mathrm{K}$ radiation diffracted at $2 \theta=156^{\circ}$ using the (211) reflection of Iron. These conditions give access to the strain localised at a depth of $6 \mu \mathrm{m}[7]$.

The analyses were performed in the longitudinal and transverse directions, in the weld toe (heat affected zone) or in the hammered zone of the plates. For each direction, 7 incidence angles $(\Psi)$ are used to obtain equivalent interval in the $\sin ^{2} \Psi$ axis $\left(0 \leq \sin ^{2} \Psi \leq 0.45\right)$. The X-Ray spot size was adapted to the measurement zone $\left(1 \mathrm{~mm}^{2}\right)$. In-depth residual stress measurements, with material removal by chemical etching, have also been performed on the fatigue samples.

Microstructural analyses has been_carried out on the weld toe before and after hammer peening by SEM/EBSD measurements on mechanically polished sections perpendicular to the weld toe and immediately below the hammering groove. Vickers microhardness tests, with a load of $10 \mathrm{~g}$, were also performed on those sections in order to obtain a hardness map within the weld toe region. Several indents were made at different positions from the sample edge (weld toe) towards the interior. For each position, the average of hardness values of three profiles is calculated. 
Four points bending fatigue tests were performed on samples designed to force crack initiation and crack propagation in the hammered zone. Figure 3 presents a schematic drawing of the sample geometry. The test frequency was fixed at $5 \mathrm{~Hz}$. Tests were performed at constant amplitude with a loading ratio of 0.1 .
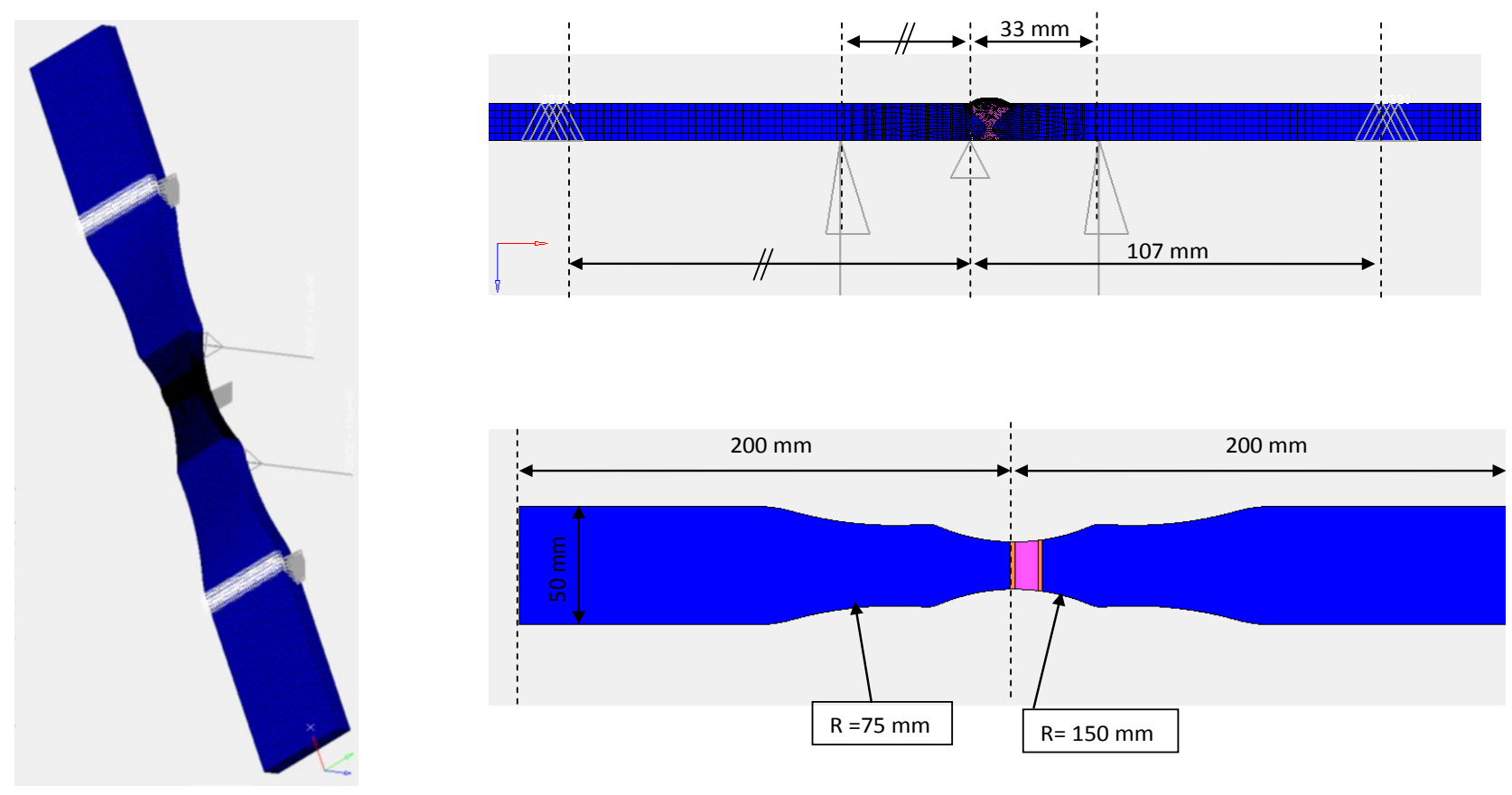

Figure 3 Schematic drawing of the four point bending fatigue samples machined from the welded plates

\section{Results and discussions}

\subsection{Samples preparation and residual stress relaxation}

As mentioned above, plates of $10 \mathrm{~mm}$ thickness have been welded in class $\mathrm{C}$. The average values of the residual stresses measured along the longitudinal and transverse directions are equal to $+200 \mathrm{MPa}$ and $-40 \mathrm{MPa}$ respectively; their sign is the expected one. Samples have been extracted by different machining methods from each welded plate. Mechanical machining with a saw was found to induce a large relaxation of the as welded residual stresses. Electrical Discharge Machining $(\mathrm{EDM})$ has then been used as an alternative: no relaxation in transverse direction and a variation of $+60 \mathrm{MPa}$ in longitudinal direction on the hammered samples were measured with this technique, which was therefore selected. The residual stresses were measured in each specimen (transversal and longitudinal directions) before fatigue testing.

\subsection{Residual stress on samples}

Figure 4 presents the average values of residual stresses for each configuration of samples tested in this study (between 10 and 20 samples by configuration). Tests have been performed on as-welded samples, on samples with post heat treatment for $1 \mathrm{~h}$ at $500^{\circ} \mathrm{C}$ for stress relaxation (as-welded, hammer peening and machined radius) and on manual hammer peening samples. It may be observed that residual stresses for as-welded samples and post-heat treatment samples are negligible and close 
to zero whilst for manual and automatic hammer peening samples, residual stresses are in compression of the order of $-350 \mathrm{MPa}$ in longitudinal direction and $-100 \mathrm{MPa}$ in transverse direction.

\subsection{Residual stress profile}

Residual stress profiles have been investigated by successive analyses after material removal by electropolishing. It may be seen on Figure 5 that on as-welded samples, no residual stress gradient exists below the surface. On welded samples with manual hammer peening, however, a residual stress gradient does exist with a residual stress level on longitudinal direction going down to $750 \mathrm{MPa}$ at $200 \mu \mathrm{m}$.

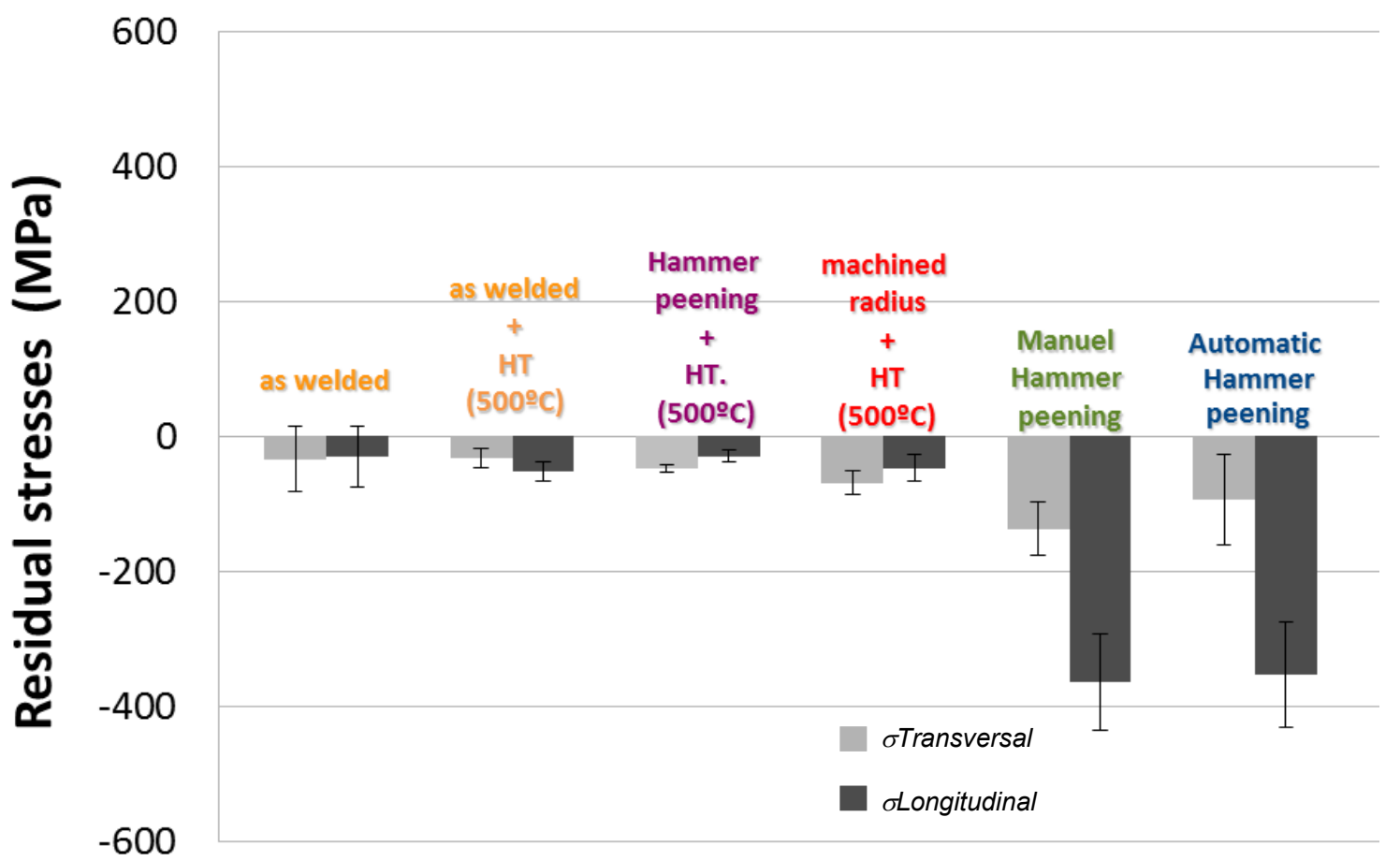

Figure 4 Surface residual stresses on samples before fatigue tests. 


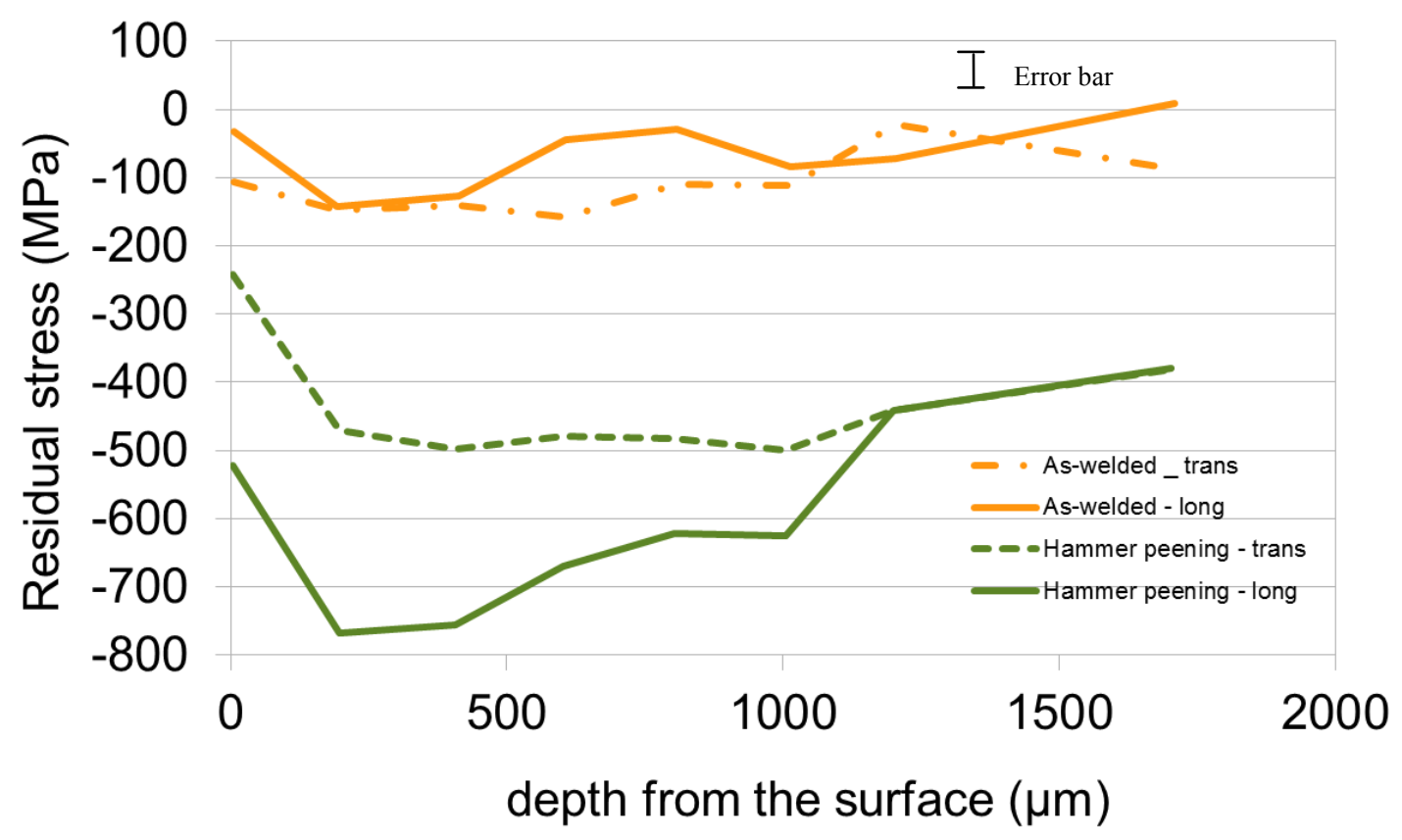

Figure 5 Residual stress profiles on as-welded sample and welded sample with manual hammer peening

\subsection{Microstructural characterization}

The microstructural evolution from the surface into the depth obtained by the EBSD technique and SEM microscopy is illustrated in Figure 6, for an as-welded sample (a), two manually hammered samples (b and c) and one automatically hammered sample (d). It can be observed that the superficial microstructure is very heterogeneous. In some cases the microstructure is slightly deformed and the initial microstructure can still be distinguished as in the case of Fig. $8 \mathrm{~b}$ ), whereas in other samples (Fig.8 $\mathrm{c}$ and d) the microstructure appears severely deformed with an ultra-fine grain microstructure. When this ultra-fine grain layer appears, it covers most of the whole cross section below the indentation left by hammering. The superficial layer consists in very fine equiaxed grains and in depth the grains are more elongated and their average size increases gradually; in the case of automatic hammering, even at $200 \mu \mathrm{m}$ below the surface the microstructure is very fine in comparison with the manually hammered sample..

The mechanical and repeated impacts applied into the surface in a short time (high strain and/or strain rate) typical of peening methods such as shot peening methods are known to produce nanograins and grain size gradient into the surface region of bulk metals and alloys [5-6]. For example, a small grain size can enhance the fatigue crack initiation threshold while coarse grains may deflect the propagation paths of fatigue cracks introducing crack closure and decreasing the rate of crack growth [4]. Since in most cases the crack, which leads to mechanical failure initiates from the surface of the work piece, components with nano or ultra-fine grain superficial layers are expected to have improved fatigue properties because both fatigue crack initiation and propagation are inhibited by the presence of fine grains near the surface and coarse grains in the interior, respectively. This effect has been well documented in the case of shot peening [5-6] but modifications of the local microstructure induced by hammering have not been reported yet. 


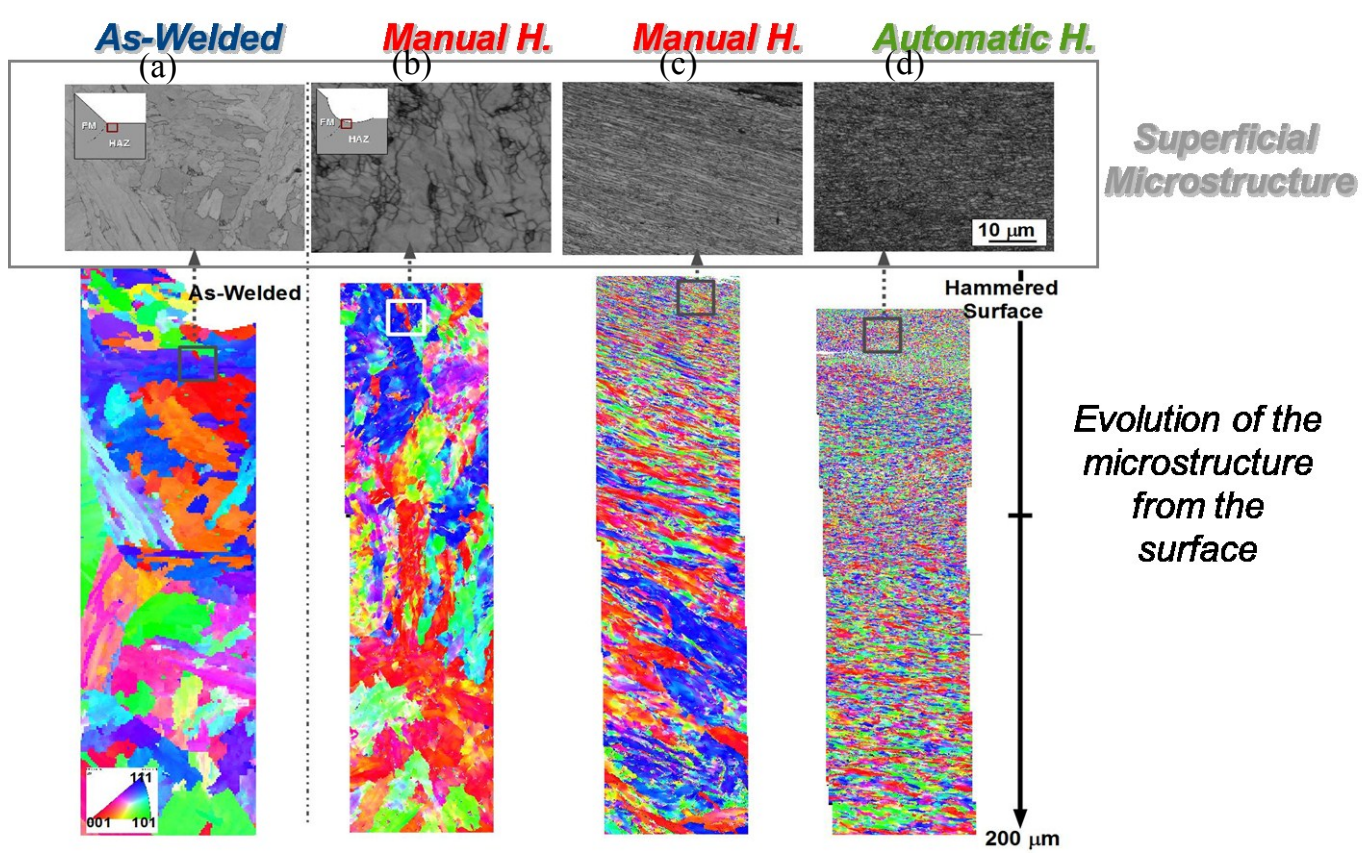

Figure 6 EBSD maps showing the evolution of the microstructure from the surface down to $200 \mu \mathrm{m}$ and SEM micrographies showing the microstructure close to the surface for a) as-welded sample, $b$ and c) manual hammered samples and d) automatic hammered samples. The magnification is the same on all images.

\subsection{Fatigue results}

The results of fatigue tests are presented in Figure 7. It can be seen on this figure, as expected that manual and automatic hammering improves the fatigue strength in comparison with as welded fatigue results. It may be assumed that the nano structure, residual stress and geometry (radius change and depth) all play an important role in this improvement.

In terms of microstructure, it may be expected to have improvement of fatigue strength when nano structures are present however for hammered samples with post-heat treatment, fatigue life is not improved in comparison with as-welded. When residual stress is not taken into account (for all samples with post heat treatment), it may be seen that fatigue results are worse than as-welded. When microstructure is taken into account, which means presence of nano grains, it may be seen that fatigue results between automatic and manual are better than as-welded results. In terms of geometry, it may be seen, as expected, no real difference in fatigue life between hammered samples and machined samples after post heat treatments however it is not expected that these results are worse than as-welded, due to the radius and depth values in table 1 . Several investigations are in progress to understand these surprising results, which no obvious explanation can be given at the moment. 


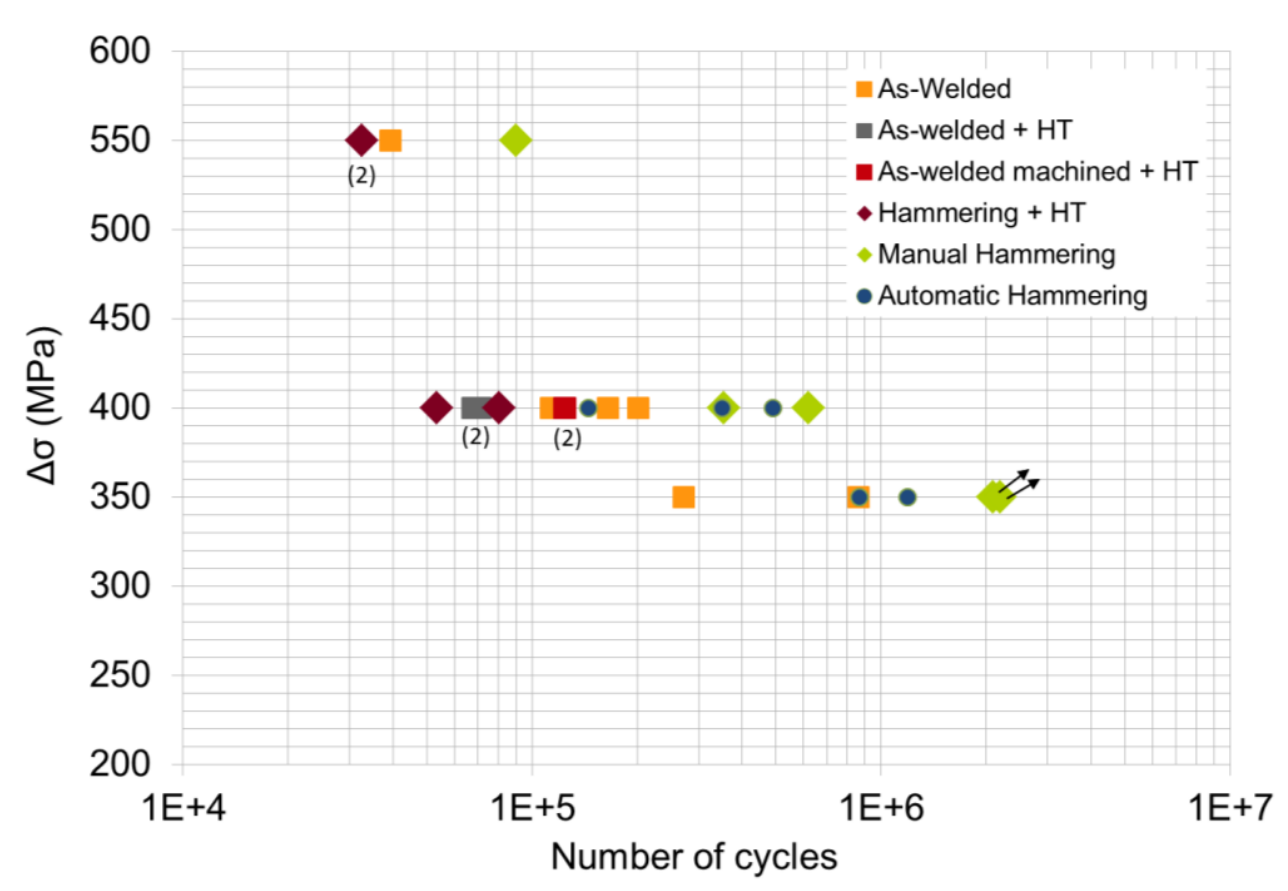

Figure 7 Fatigue results for different configurations.

\section{Conclusions}

The fatigue lives (four point bending tests $\mathrm{R}=0.1$ ) of butt welds of the $\mathrm{S} 690$ steel has been improved by the hammer peening procedure. The presence of compressive residual stresses arising from the hammering process certainly takes part in the increase of fatigue life. In general, at the surface of the weld toe, the residual stress in the longitudinal direction is more important than in the transverse direction. Moreover, the in-depth residual analysis shows that hammering introduces higher compressive residual stress around $200 \mu \mathrm{m}$ depth. It may be also noted that stress relaxation occurs during machining and so special care needs to be taken into account in the preparation of fatigue samples, which means, in this study, that welding and hammering should be performed on pre-machined samples.

The plastic deformation introduced by the hammer may have created below the surface a strain hardened region. Its thickness varies depending on the position along the weld toe.

An ultra-grain fine superficial layer has been detected at the welded toe of hammered samples. The presence of this region is likely to improve the fatigue life of hammer samples as it is correlated with even higher values of hardness, however, this point requires further investigation.

At this stage of the study, it is not possible to know the exact contribution of the different modifications introduced by the hammering procedure (compressive residual stress, strain-hardened region, stress concentration, ultra-fine superficial layer...) that can take part in to fatigue life improvement. 


\section{References}

[1] M. Leitner and M. Stoschka, Influence of steel grade on the fatigue strength enhancement by high frequency peening technology on longitudinal fillet weld gusset. Journal of Engineering and Technology, 1(3) (2001) 80-90

[2] G. Marquis, Engineering Fracture Mechanics, Failure modes and fatigue strength of improved HSS welds, 77 (2001) 2051-2062

[3] P. J. Haagensen, S. M. Maddox, International Institute of Welding: March 2009 (Document IIW-XIII-2200r3-07 )

[4] T. Hanlon, Y. N. Kwon, S. Suresh, Grain size effects on the fatigue response of nanocrystalline metals, Scripta Materialia, 49 (2003) 665-680

[5] D. J. Child, G. D. West, R. C. Thomson, Assessment of surface hardening effects from shot peening on a Ni-based alloy using electron backscaterdiffraction techniques, Acta Materialia, 59 (2011) 4825-4834.

[6] L. L. Shaw et al. A direct comparison in the fatigue resistance enhanced by surface severe plastic deformation and shot peening in a C-2000 superalloy Materials Science and Engineering A, 527 (2010) 986-994.

[7] EN 15305 standard: Test methods for residual stress analysis by X-ray

[8] ISO 5817 - Welding - Fusion-welded joints in steel, nickel, titanium and their alloys (beam welding excluded) - Quality levels for imperfections 